\section{International Scientific Journal Theoretical \& Applied Science}

\author{
p-ISSN: 2308-4944 (print) e-ISSN: 2409-0085 (online) \\ Year: 2014 Issue: 12 Volume: 20 \\ Published: $30.12 .2014 \quad$ http://www.T-Science.org
}

SECTION 21. Pedagogy. Psychology. Innovation in
Sergey Ivanovich Kondrat'ev Professor, Doctor of Technical Sciences, Rector of the State Maritime University Admiral Ushakov, Russia, mail@,nsma.ru

Natalya Borisovna Khmeleva Associate Professor, Assistant professor Department of Foreign Languages, State Maritime University Admiral Ushakov, Russia, khmelevan@gmail.com

Education.

\title{
FORMING OF PROFESSIONAL COMPETENCE BY SIMULATOR TRAINING AS MEANS OF PROVIDING SAFETY OF NAVIGATION
}

Abstract: Scientific basing of forming seafarers 'professional communicative competence while simulation training as means of providing safety of navigation is given in this article. Innovative basic working definitions of simulation training not found in native pedagogy are offered.

Key words: system of education improvement, innovative, professional communicative activity, problem of safety of navigation, poly-profiled professional training, case-study, simulator, knowledge-ability-skill, competency, module.

Language: Russian

Citation: Kondrat'ev SI, Khmeleva NB (2014) FORMING OF PROFESSIONAL COMPETENCE BY SIMULATOR TRAINING AS MEANS OF PROVIDING SAFETY OF NAVIGATION. ISJ Theoretical \& Applied Science 12 (20): 16-21. doi: http://dx.doi.org/10.15863/TAS.2014.12.20.5

\section{УДК 372.851}

\section{ФОРМИРОВАНИЕ ПРОФЕССИОНАЛЬНОЙ КОМПЕТЕНЦИИ В ПРОЦЕССЕ ТРЕНАЖЕРНОЙ ПОДГОТОВКИ - ФАКТОР ОБЕСПЕЧЕНИЯ БЕЗОПАСНОСТИ СУДОВОЖДЕНИЯ}

Аннотация: В статье научно обоснована необходимость формирования профессиональной коммуникативной компетенциии специалистов морского флота в рамках тренажерной подготовки как средстве обеспечения безопасности судовождения. Предлагаются рабочие определения базовых инновационных понятий системы тренажерной подготовки, не обнаруженные в отечественной дидактике.

Ключевые слова: совершенствование системы образования, профессиональная коммуникативная деятельность, проблема безопасности, полипрофильная профессиональная подготовка, тренажер, проблемная производственная ситуация, компетентность, модуль.

Актуальность возросших требований к совершенствованию системы современного морского образования [1] диктует необходимость поисков инновационных методов и приемов повышения эффективности учебного процесса. Такая необходимость не является дидактической самоцелью, а диктуется реальным состоянием в сфере подготовки современных специалистов транспорта как в силу внешних по отношению к системе образования изменившихся обстоятельств и вызовов, так и внутренних квалификационных параметров профессиональной подготовки современных специалистов флота.
К числу внешних факторов относятся: давление сформировавшихся и формирующихся кардинальных изменений: 1) геополитического характера [3]; 2) мировой экономики, международной интеграции и кооперации, которые повлекли за собой рост интенсивности межгосударственных и экономических связей, что обусловило увеличение интенсивности работы флота и рост объемов перевозимых грузов, а так же увеличение пассажиропотоков на всех видах транспорта, что неизбежно способствовало обострению конкурентной состязательности и борьбы за рынки и преференции; 3) социо-культурного плана взаимодействия современных социумов; 4) 
юридических и правовых параметров такого взаимодействия в условиях усложнившейся экологической ситуации в мире и беспрецедентного ущерба в связи с увеличением количества крупных катастроф (типа катастрофы в Мексиканском заливе) $[1,6]$.

К числу внутренних факторов влияния на профессиональную подготовку современных специалистов флота относятся неизбежное увеличение: 1) профессиональной нагрузки на их деятельность в условиях выполнения международного рейса в связи с ростом интенсивности морского трафика; 2) психологической нагрузки в силу вышеперечисленных внешних факторов; 3) все возрастающих требований не только российских государственных образовательных стандартов ВПО направления подготовки [8] и дипломирования специалиста эксплуатации водного транспорта и транспортного оборудования 658000 по специальности *Судовождение* 180402,и квалификационными требованиями *Международной конвенции о подготовке и дипломировании моряков и несения вахты 78/95,* а так же текущими требованиями, регулярно публикуемыми Международной морской организацией ( ИМО ) по вопросам судовождения [9]; 4) продолжающийся рост аварийности на морском транспорте, уносящем ежегодно тысячи человеческих жизней в связи с гибелью больших и малых судов [10].

Совокупность перечисленных факторов, к которым добавилось давление современного мирового экономического кризиса с неизбежными изменениями в сфере занятности специалистов, диктует объективную необходимость поисков в совершенствовании образования [5] как компонента единого мирового образовательного процесса, что составляет его внутреннюю сущность.

При рассмотрении основных параметров производственной деятельности будущих специалистов морского флота, в частности, судоводителей, в поисках инновационных подходов к повышению их профессионального уровня подготовки, как представляется, необходимо исходить из полипрофильной [4] по своей сущности характеристики их деятельности, поскольку она на практике фактически реализуется в комплексе системы социальных, профессиональных и межличностных отношений; в условия выполнения целесообразной деятельности во время международного рейса при необходимости соблюдения многочисленных современных российских и международных конвенционных требований.
Полипрофильный характер деятельности судоводителя определяет необходимость его профессиональной подготовки на основе множественных связей и отношений комплекса межпредметной ориентации с другими дисциплинами базового профиля, существенными для данной специальности при абсолютной необходимости выполнения производственной деятельности в условиях коммуникации на английском языке (продолжающем оставаться единственным языком интернационального общения) при выполнении международного рейса, как правило, в смешанных интернациональных экипажах.

При этом комплексная и динамичная по своей природе профессиональная деятельность специалиста морского флота должна обеспечить безопасность судовождения как краеугольную цель осуществления такой деятельности. Это приобретает особую значимость в рамках общей проблемы безопасности на водном транспорте, где проблема безопасности для судоводителей понимается максимально широко, как безопасность 1) жизни, 2) судна, 3) груза, 4) защита окружающей среды.

Предметная область специальности судоводителя в её базовом наполнении состоит из: навигации, теории устройства судна ,метеорологии, географии морского судоходства ,математических основ судовождения, астрономии ,технических средств судовождения, экономики водного транспорта, морского права, обеспечение безопасности жизнедеятельности , английского языка и т.д.

На основе изучения этих составляющих и базовых основ поля профессиональной характеристики специальности судоводителя практически критического объема ( и потому трудно усваиваемого обучаемыми) должны быть сформированы базовые знания как компетенции в области перечисленных конкретных профессиональных дисциплин.

При этом полученный результат такого обучения в известной дидактической цепочке «знания - умения - навыки» может быть достигнут бесспорно только по первому параметру, и в лучшем случае частично - по второму, что не может быть достаточным ни в силу сущности специфики профессии судоводителя, ни в силу требований современного образовательного госстандарта, предъявляемых к этой специальности.

«На выходе» при таком подходе логично и контролируется практически уровень полученных/усвоенных знаний составляющих параметров этой дисциплины, как правило, в виде экзамена. 
Что касается английского языка как базового компонента профессиональной характеристики специальности судоводителя, то здесь находит подтверждение лингвистическое обоснование понимания представления о речевой деятельности в соотношении языка как системы, и речи, прозорливо обоснованное еще академиком Л.В.Щербой [7]. При традиционном подходе к системе обучения в дидактической цепочке на практике обеспечивается в лучшем случае обучение языку как системе (его фонетического, лексико-грамматического строя). При этом собственно речевая деятельность, а в нашем понимании-полипрофильная речевая деятельность (ПРД) как профессиональная иноязычная коммуникация оказывается за пределами возможностей достижения цели формирования навыков, адекватный уровень которых может быть сформирован при включении фактора производственной деятельности в конкретных производственных ситуациях,но это фактически недостижимо в условиях учебного аудиторного занятия в связи с объективным отсутствием сложного комплекса современной и адекватной техникотехнологической поддержки реального осуществления практической деятельности судоводителя.

Вероятно, именно этим и объясняются некоторые возникающие недоработки в иноязычной подготовке наших выпускников, что и обуславливает необходимость дальнейших поисков путей совершенствования и оптимизации учебного процесса в вузе типа морского с его спецификой в плане требований к языковой подготовке специалистов.

С учетом изложенного, представим схему образовательного процесса при традиционном подходе.

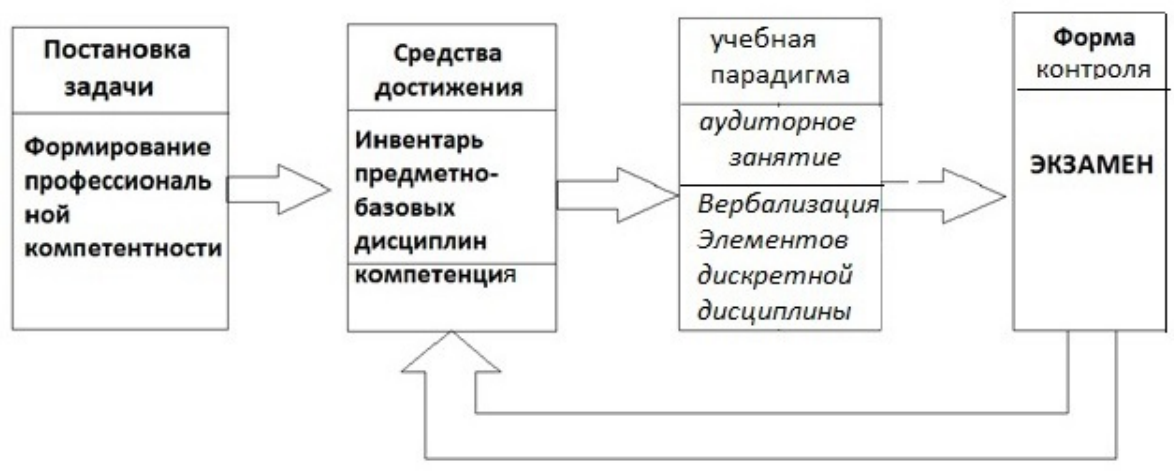

Рисунок 1 - Схема образовательного процесса при традиционном подходе.

Причем эта учебно-образовательная парадигма практически соответствует тем Колумбовским временам, когда техническая поддержка специальности судоводителя сводилась к триаде: компас-руль-паруса, да попутный ветер.

Изменение технологии судовождения, включившей в себя все самые современные технологические достижения науки, техники и практики в ответ на изменившийся геополитический порядок, объективно требует поиска совершенствования образовательного процесса с тем, чтобы: 1) обеспечить оптимальную адекватность его соответствия уровню современных требований и вызовов; 2) по возможности снизить безусловно возросшую до критического объема интеллектуальную и психологическую нагрузку на специалиста современного флота, порой блокирующую успешность выполнения ими своих должностных обязанностей (вспомним одиозные бесконечные авралы в работе помощников капитана при оформлении подхода/выхода из любого порта захода).

Обращение к тренажерной подготовке в рамках поисков инновационных подходов оказалось таким оптимальным приемом обеспечения необходимого уровня подготовки специалистов профессий экстремального риска и ответственности - космонавтов, летчиков, моряков, чья производственная деятельность объективно имеет не только полипрофильный характер, но к тому же связана чаще всего с изменением внешней естественной среды обитания, и кроме того, обусловлена необходимостью коммуникации на (не родном) английском языке как условии выполнения профессиональных задач.

В таких областях деятельности обращение к тренажерной подготовке оказывается хотя и 
высоко затратным, но наиболее эффективным техническим приемом, изменяющим технологию обучения, который реально способствует выработке навыков и совершенствованию умений у обучаемых, поскольку может:

1) обеспечить максимальное приближение, имитацию реальных технологических условий выполнения производственной деятельности специалистов в конкретных заданных ситуациях при решении поставленной производственной проблемной задачи,

2) задать практически любые производственно-необходимые

пространственные, временные параметры осуществления такой деятельности при решении задачи в штатных и типичных ситуациях с целью выработки автоматизированного производственно поведенческого алгоритма действий,

3) гибко изменять параметры штатной ситуации путем введения в нее максимально возможных и необходимых параметров множества профессионально-релевантных характеристик, прогнозируя их возможность в будущем так, чтобы гарантировать выработку принятия правильного решения с целью избежания аварии в нештатной экстремальной ситуации, что и будет означать на практике обеспечение безопасности судовождения.

Цель включения тренажерной подготовки в учебный процесс состоит в том, чтобы при правильном педагогическом управлении на определенном этапе перевести теоретические знания разных и достаточно дискретно преподаваемых, очень объемных дисциплин в подготовку, отражающую реальную полипрофильную деятельность судоводителя. Такой сдвиг или смещение осуществляется на основе межпредметных связей комплекса базовых профильных дисциплин, который реализуется в ориентированных на предвосхищение моделируемых ситуациях так, чтобы объективно достаточные знания одной дисциплины и сформированные в ней компетенции обучаемые могли использовать в другой дисциплине, вырабатывая целесообразные навыки и умения их реального применения в практической области. В этом случае навыки и умения моделируются в комплекс ответных поведенческих реакций и профессиональных действий; таким образом, обеспечивая новый, оптимальный уровень реальной профессиональной компетентности согласно международных и государственных конвенционных требований и усложнившихся условий международной экономической интеграции.
Такая организация учебного процесса означает выделение (по усмотрению преподавателя) в рамках специальности базового, сущностно-инвариантного ядра конкретного предмета в достаточном и целесообразном объеме, который обеспечил бы достижение цели деятельности специалиста в её прикладном, прагматическом аспекте.

Включение тренажерной подготовки в образовательный процесс означает и включение в качестве интегрирующей ту самую “'коммуникационную составляющую”, которая объединяет практически все стороны профессиональной деятельности судоводителя. Она оказывается своего рода интегрирующей "сетью”, которая накладывается на все базовые компоненты деятельности судоводителя, "запуская" её в многочисленных конкретных производственных ситуациях выполнения международного рейса, подлежащих отработке на тренажерах.

Под тренажерной подготовкой применительно к профессии судоводителя мы предлагаем понимать технологию обучения, представляющую собой комплекс педагогических приемов, направленных на:

1) выработку у обучаемых производственнокоммуникативных алгоритмов оперативного решения типовых производственных задач

2) как стандартизированных действий при штатном режиме деятельности , допускающей на начальном этапе многовариантность решения задач на основе выбора из совокупности некоторого множества с целью

3) предвосхищения возможности принятия минимального инвариантного решения, способного гарантированно обеспечить безопасность (жизни, судна и окружающей среды) в случае возникновения нештатной экстремальной ситуации.

Условной единицей технологии тренажерного обучения предлагаем считать конкретную проблемную профессиональную штатную производственную ситуацию с постановкой сформулированной задачи по оптимальному достижению результата при условии заданности параметров и времени на её решение при обязательном мониторинге достижения / не достижения поставленной цели.

Тренажерное обучение представляет собой завершающий этап профессионального обучения будущих специалистов, поскольку основывается и требует достаточного объема комплекса накопленных базовых компетенций полипрофильной специальности судоводителя.

$$
\text { Из трех основных известных [2] }
$$
функциональных типов тренажеров :1) 
понятийные (интеллектуальные), 2) участковые (локальные) и 3) полномасштабные (комплексные) наиболее перспективными оказываются безусловно полномасштабные тренажеры типа Navi-Trainer Professional производства Группы Transas.

Тренажер ГМССБ TGS 5000 предназначен и используется для подготовки и сертификации судовых специалистов, получающих диплом оператора ГМССБ (GOC) или диплом оператора ограниченного района ГМССБ. На этом тренажере также успешно осуществляется обучение операциям по осуществлению поисково-спасательных операций (SAR), а также обучение оператора СУДС. Тренажер обеспечивает проведение следующих видов подготовки в соответствии с международными и национальными стандартами: организация ходовой навигационной вахты, маневрирование и управление судном, защита морской окружающей среды, радиолокационное наблюдение и прокладка курса, использование АИС и другие.

Тренажер грузо-балластных операций наливного судна LCHS-5000 предназначен для тренировки команды танкера и персонала терминалов наливных грузов по обработке этих грузов и эксплуатации вспомогательного грузового оборудования в соответствии с конвенционными требованиями международного стандарта и т.д.

Bce эти составляющие параметры практической профессиональной деятельности судоводителя могут быть отработаны в конкретных проблемных ситуациях с максимальной имитацией технологических параметров реальных условий такой деятельности .

При включении тренажерной подготовки в образовательный процесс его схема приобретает вид завершенного динамичного и самостоятельного модуля, в котором обеспечивается необходимый комплекс оптимального соответствия и совпадения теоретических знаний и практических требований области их применения на основе формирования параметров искомой профессиональной компетентности.

Схема включения тренажерной подготовки в учебный процесс может быть представлена в следующем виде.

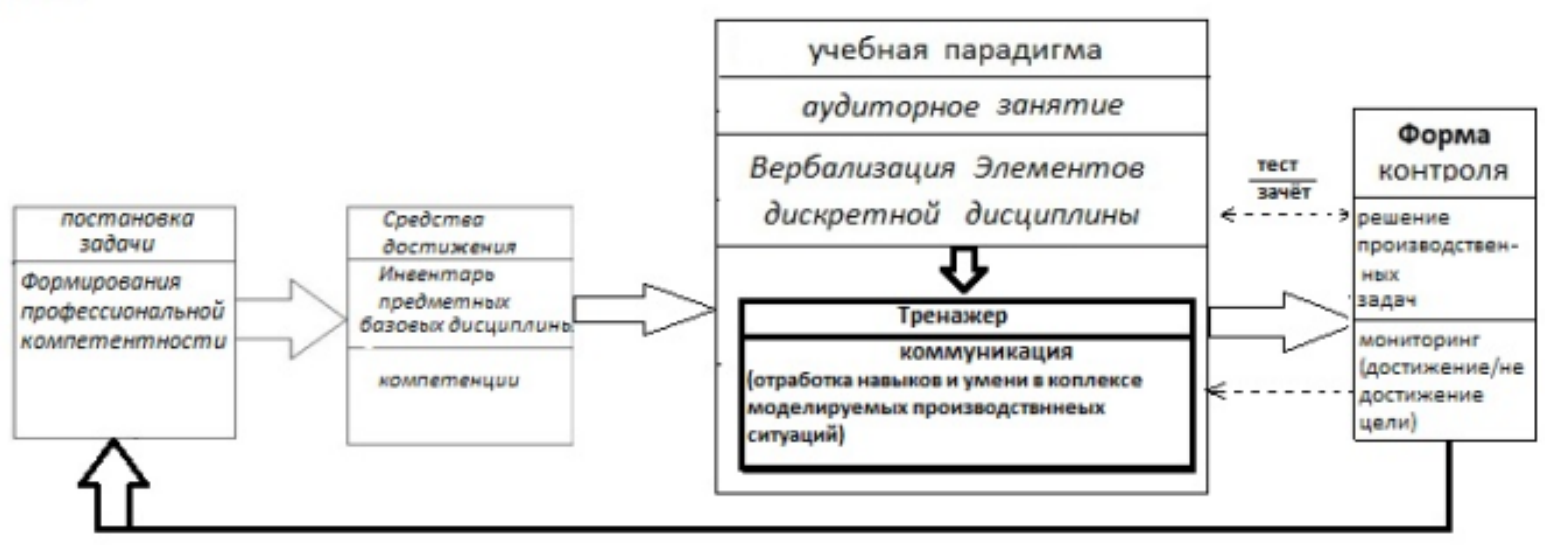

Рисунок 2 - Схема образовательного процесса при модульном подходе.

Таким образом, несколько упрощая ситуацию отметим, что принципиальная разница между традиционной организацией учебного процесса и его модульной организацией с включением тренажерной подготовки состоит в том, что в первом случае искомый результат квалификация специалиста - представляет собой практически накопленную сумму знаний узкой профессиональной направленности как инвентаря компетенций, которые практически и подлежит «на выходе» контролю чаще всего в виде экзамена.
Во втором случае мы имеем динамичный комплекс навыков и умений искомой сформированной профессиональной интегрированной деятельности как компетентности, гарантирующей адекватный уровень способности выполнения комплекса профессиональных производственных задач.

Практика привлечения курсантов к работе по обучению на перечисленных тренажерах, моделирующих основной спектр их полипрофильной деятельности, позволяет достичь желаемого результата по обучению 
адекватному выполнению технологических операций как в штатных, так и в экстремальных производственных ситуациях.

\section{Выводы.}

Таким образом, в сложной иерархии структуры профессиональной подготовки специалиста полипрофильной специальности современного судоводителя, включение тренажерной подготовки в учебный процесс

1) позволяет свести воедино комплекс базовых знаний предметного плана содержания специальности и перевести его в реальное поле деятельности -функционирование путем вербализации коммуникативно-релевантных этой специальности навыков и выработке умений в моделируемых на тренажерах проблемных штатных и типичных ситуациях с вектором их направленности на будущее упреждение в ситуациях нештатных и экстремальных с целью исключения возможности возникновения последних в реальной будущей деятельности.

2) Как показала практика работы на 5-6 курсах судоводительской специальности очного и заочного факультетов, такое включение тренажерной подготовки максимально повышает мотивацию учебной деятельности обучаемых, активизирует их интеллектуальные и творческие способности, вызывает естественный интерес, и в целом интенсифицирует весь учебный процесс.

3) В совокупности это на практике одновременно и означает возможность выработки навыков и умений по обеспечению той искомой и заветной многосторонней безопасности мореплавания, понимаемой максимально широко -как безопасности жизни, судна, груза и окружающей среды.

При включении тренажерной подготовки в образовательный процесс он приобретает организационную форму динамичного и самостоятельного модуля, включающего в себя оптимальный комплекс прагматически обусловленных, достаточных и необходимых (сформированных на основе базовых знаний) умений и навыков профессиональных характеристик специалиста флота, реализуемых в конкретных проблемных профессиональных производственных ситуациях, формирующих адекватный уровень их профессиональной компетентности.

При таком подходе круг целей, задач и средств их достижения логически замыкается, реально обеспечивая требуемый уровень подготовки современного и конкурентно способного специалиста флота.

\section{References:}

1. Deruzhinskij VE, Marichev IV (2014) Sovremennyj ehtap reformirovaniya vysshej shkoly. Ehkonomika ustojchivogo razvitiya. No. 1 (17). pp. 53-53.

2. Zajcev VK (2014) Teoreticheskie osnovy informacionno-trenazhernykh tekhnologij obucheniya, podgotovki i reabilitacii cheloveka-operatora. Available: http://combitt.narod.ru/project/sbor...

(Accessed: 10.12.2014).

3. Kondrat'ev SI (2012) Strategiya razvitiya transportnogo kompleksa yuga Rossii v usloviyakh glo-balizacii ehkonomiki. Vestnik gosudarstvennogo morskogo universiteta imeni adm. F.F.Ushakova, Novorossijsk, No.1(11), 2012. pp. 5-9.

4. Makashina II (2007) Podgotovka menedzherov dlya morskogo flota. Monografiya. M-vo obrazovaniya I nauki Rossijskoj Federacii, Kubanskij gos. un-t. Krasnodar, pp. 320.

5. Marichev IV (2008) Morskoe obrazovanie kak kom-ponent edinogo mirovogo obrazovatelnogo processa. Vysshee obrazovanie segodnya. 2008. No. 5. pp. 50-53.

6. Khmeleva NB (2013) «Be Ready to Prevent Pollution». Uch. Posobie - RIO FGBOU VPO «Morskaya gosudarstvennaya akademiya imeni adm. F.F.Ushakova», Novorossijsk, pp.35.

7. Shcherba LV (1974) Prepodavanie inostrannykh yazykov v srednej shkole. Monografiya. - Yazykovaya sistema I rechevaya deyatelnost. «Nauka», Leningrad, pp.380.

8. (1989) Sbornik Rezolyucij mezhdunarodnoj Morskoj organizacii po voprosam sudovozhdeniya. - $\quad$ Moscow: V/O Mortekhreklama, pp.15.

9. (1966) "STCW-78, Chapter VIII. Standards Regarding Watchkeeping, S-Pb.: ZOO CNIIMF.

10. Richard Clyton (2009) "Talant in Time." "Fairplay", 30 Apr., 2009, pp.12. 